Article

\title{
Estimation of Transformers Health Index Based on the Markov Chain
}

\author{
Muhammad Sharil Yahaya ${ }^{1,2}$, Norhafiz Azis ${ }^{1,3, *}$, Mohd Zainal Abidin Ab Kadir ${ }^{1}$, \\ Jasronita Jasni ${ }^{1}$, Mohd Hendra Hairi ${ }^{4}$ and Mohd Aizam Talib ${ }^{5}$ \\ 1 Centre for Electromagnetic and Lightning Protection Research, Universiti Putra Malaysia, \\ 43400 Serdang, Selangor, Malaysia; sharil@utem.edu.my (M.S.Y.); mzk@upm.edu.my (M.Z.A.A.K.); \\ jas@upm.edu.my (J.J.) \\ 2 Faculty of Engineering Technology, Universiti Teknikal Malaysia Melaka, Hang Tuah Jaya, \\ 76100 Durian Tunggal, Melaka, Malaysia \\ 3 Institute of Advanced Technology (ITMA), Universiti Putra Malaysia, 43400 Serdang, Selangor, Malaysia \\ 4 Faculty of Electrical Engineering, Universiti Teknikal Malaysia Melaka, Hang Tuah Jaya, \\ 76100 Durian Tunggal, Melaka, Malaysia; hendra@utem.edu.my \\ 5 TNB Research Sdn. Bhd., No. 1, Lorong Ayer Itam, Kawasan Institut Penyelidikan, \\ 43000 Kajang, Selangor, Malaysia; aizam.talib@tnb.com.my \\ * Correspondence: norhafiz@upm.edu.my; Tel.: +60-3-8946-4373
}

Received: 28 September 2017; Accepted: 24 October 2017; Published: 10 November 2017

\begin{abstract}
This paper presents a study on the application of the Markov Model (MM) to determine the transformer population states based on Health Index (HI). In total, 3195 oil samples from 373 transformers ranging in age from 1 to 25 years were analyzed. First, the HI of transformers was computed based on yearly individual oil condition monitoring data that consisted of oil quality, dissolved gases, and furanic compounds. Next, the average HI for each age was computed and the transition probabilities were obtained based on a nonlinear optimization technique. Finally, the future deterioration performance curve of the transformers was determined based on the $\mathrm{MM}$ chain algorithm. It was found that the MM can be used to predict the future transformers condition states. The chi-squared goodness-of-fit analysis revealed that the predicted $\mathrm{HI}$ for the transformer population obtained based on MM agrees with the average computed $\mathrm{HI}$ along the years, and the average error is $3.59 \%$.
\end{abstract}

Keywords: transformers; Health Index (HI); Markov Model (MM); nonlinear optimization; transition probabilities; deterioration performance curve; chi-squared goodness-of-fit; asset management

\section{Introduction}

Transformers are counted among the important assets in a power system network, failures of which could lead to costly consequences. Failures of transformers can be initiated by several factors such as design issues, unusual loadings, electrical faults, and advanced degradation of insulations. According to References [1,2], the degradation of transformers is a complex phenomenon that can be affected by several factors. Nowadays, the majority of utilities have implemented Condition-Based Management (CBM) to closely monitor the condition states of transformers. Through this approach, the management strategies of the assets can be improved and the cost can be reduced as compared to previous Time-Based Management (TBM). CBM utilizes overall condition monitoring data from transformers and provides possible actions that can be carried out by utilities [2-4]. Under CBM, a single quantitative assessment known as Health Index (HI) is normally formulated to provide the overall condition of transformers. HI normally consists of multiple input parameters such as oil condition monitoring data, loadings, design, location, and electrical/mechanical integrities [5-11]. 
HI provides a comprehensive condition assessment of transformers as compared to Dissolved Gases Analysis (DGA), which mainly focuses on the identification of faults [5]. Conventionally, HI is used to determine the current state of transformers and there is a potential to utilize $\mathrm{HI}$ for future states predictions. Common mathematical approaches such as regression, fitting, and extrapolation techniques are not suitable due to the overreliance on the data, which may affect the reliability of predictions [12-14]. Currently, there are still less studies that have been carried out to model the future condition states of transformers based on HI. Other studies, such as those in References [6,9,15-17], mainly focused on the utilization of the $\mathrm{HI}$ to determine the future reliability of transformers and its impact on the power system network. The Markov Model (MM) is identified as one of the prediction methods that can be used to determine the future states of transformers based on HI. It is based on a probability decision process where future decisions on maintenance schemes depend on actual assets performances $[14,18,19]$. MM had been widely implemented in References [14,18-28] to model the deterioration of different types of equipment. In civil engineering, $\mathrm{MM}$ had been applied in References [14,18-24] to model the degradation of bridge deck and elements, pavement, water piping components, and steel hydraulic structures. MM had also been utilized in References [25-28] for electrical equipment such as modeling the condition of switchgear oils, the identification of faults, and transformers spare units. In this study, an innovative approach is proposed that utilizes MM to determine the deterioration performance curve based on computed HI from the transformer population. The approach can be used to estimate the future condition of the transformer population with less complexity and the prediction data can be updated dynamically. In total, the oil condition monitoring data from 373 distribution transformers with ratings of $33 \mathrm{kV}$ and $30 \mathrm{MVA}$ are used for the case study. Next, the $\mathrm{HI}$ is computed based on a scoring method and the future condition states of transformers are predicted based on MM.

\section{Condition Assessment and Health Index (HI)}

The overall condition of transformers is normally monitored through the Health Index (HI). $\mathrm{HI}$ is defined by Reference [29] as an approach to quantify transformers condition monitoring information for asset management purposes. Nowadays, HI is adopted by most of the utilities in the world $[5,7,8,10,11,30]$. The conventional concept of $\mathrm{HI}$ formulation is based on a scoring method that is based on weighting and ranking techniques [29-31]. There were also a number of advanced methods that had been proposed to determine the HI [32,33]. These techniques are quite complex and require extensive information to compute the HI. In this study, the scoring method was chosen for the computation of HI due its simplicity, adaptability with the readiness of data, and the fact that it is most commonly used by utilities nowadays. Figure 1 shows the HI computation principle for a single condition monitoring data based on the scoring method [30].

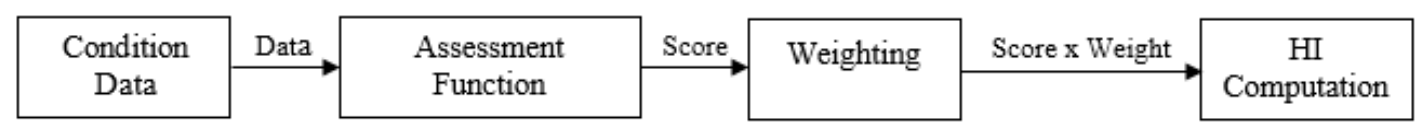

Figure 1. Health Index (HI) scoring method computational principles for single condition monitoring data (adapted from [30]).

The condition data are extracted from the condition monitoring information and physical observations. The assessment function is defined based on standards, guidelines, historical information, and theoretical knowledge. Expert judgement and statistical record are usually utilized to determine the weighting factors. In this study, the oil quality parameters considered were AC breakdown voltage, moisture in oil, acidity, color, and interfacial tension. In total, seven gases were considered, including hydrogen, methane, ethane, ethylene, acetylene, carbon monoxide, and carbon dioxide. First, the score and weighting factors for individual parameters were obtained according to the corresponding ranges in References [5,31]. Next, the factors for oil quality and dissolved gases were 
computed according to References [5,31]. The next step was to determine the factors for oil quality and dissolved gases in oil according to Equation (1).

$$
D G F \text { or } O Q F=\frac{\sum_{i=1}^{n} S_{j} \times W_{j}}{\sum_{i=1}^{n} W_{j}}
$$

where $W_{j}$ is the weighting factor for each parameter, $n$ is the number of parameters in each factor, and $S_{j}$ is the score for each parameter. Finally, the rating codes for both parameters were determined from the rating code table in References [5,31]. For furanic compounds, the rating codes were determined directly from the rating code table in References [5,34]. Based on the rating codes for all parameters, the final HI was computed according to Equation (2). Equation (2) is based on References [5,31,34], where the modification was carried out by the removal of percentage ratios for transformers and tap changers, as only transformers data could be obtained in this study.

$$
H I=\frac{K_{D G A} H I F_{D G A}}{4 K_{D G A}}+\frac{K_{O Q A} H I F_{O Q A}}{4 K_{O Q A}}+\frac{K_{F A} H I F_{F A}}{4 K_{F A}}
$$

where $K$ is the rating given to each factor, and HIF is the score of each factor.

\section{Development of the Markov Model (MM)}

\subsection{Markov Chain Modeling Concept}

In this study, $\mathrm{MM}$ is implemented to determine the future condition of the transformers population based on HI. The overall process of the approach in this study can be seen in Figure 2.

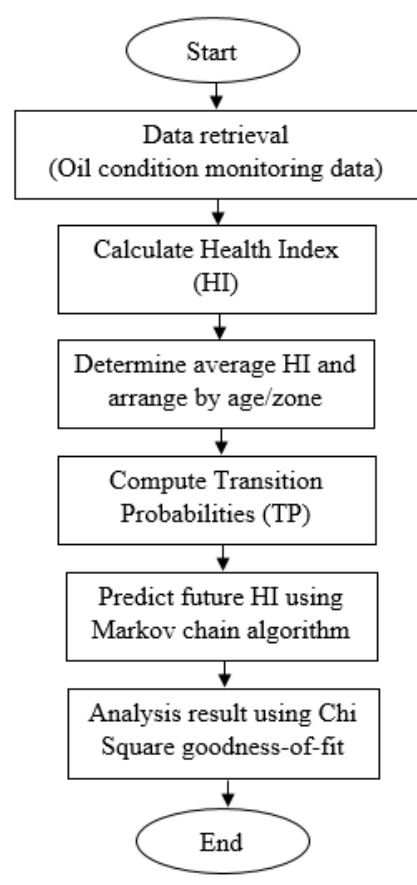

Figure 2. Modeling process of deterioration performance curve based on the Markov Model (MM).

According to References $[18,35,36]$, the Markov decision process is normally characterized as a memoryless process where it predicts the future condition of equipment as a probabilistic estimate. The Markov chain depends on the transition probabilities given as $P_{i j}$ [18,36]. $P_{i j}$ is the probability of equipment decaying from state condition $i$ to $j$ in a specific interval time. A set of transition probabilities can be represented in a form known as the transition matrix, $\boldsymbol{P} . P_{i j}(t)$ has the same value 
in a specific year and each state probability must be equal to 1 , for example, $P_{11}+P_{12}=1, P_{22}+P_{23}=1$, $P_{33}+P_{34}=1$, and $P_{44}+P_{45}=1$. Equation (3) shows the formulation of the transition matrix for five state conditions used in this study.

$$
\boldsymbol{P}=\left[\begin{array}{ccccc}
P_{11} & 1-P_{11} & 0 & 0 & 0 \\
0 & P_{22} & 1-P_{22} & 0 & 0 \\
0 & 0 & P_{33} & 1-P_{33} & 0 \\
0 & 0 & 0 & P_{44} & 1-P_{44} \\
0 & 0 & 0 & 0 & 1
\end{array}\right]
$$

Once the yearly $\mathrm{HI}$ of all transformers were computed based on Equation (2), the average HI based on age was determined and plotted. The plot trend was defined as the computed transformers life deterioration performance curve and used for the modeling purposes of MM. The HI indicator scales and states used for the MM were obtained from References [5,31], and can be seen in Table 1.

Table 1. HI indicator scales and states (adapted from $[5,31]$ ).

\begin{tabular}{cccc}
\hline State & $\begin{array}{c}\text { Health } \\
\text { Index }\end{array}$ & Condition & Description \\
\hline 1 & $85-100 \%$ & Very Good & Some aging or minor deterioration of a limited number of components. \\
2 & $70-84 \%$ & Good & Significant deterioration of some components. \\
3 & $50-69 \%$ & Fair & Widespread significant or serious deterioration of specific components. \\
4 & $30-49 \%$ & Poor & Widespread serious deterioration. \\
5 & $0-29 \%$ & Very Poor & Extensive serious deterioration. \\
\hline
\end{tabular}

Several assumptions were made to analyze the HI of transformers based on the MM. First, the deterioration process of transformers was considered as a monotonic and irreversible process. Thus, the condition of transformers either remained in its existing condition group or moved to the next state condition group. In order to develop the homogeneity of the deterioration performance curve, the transition probabilities were determined based on the transformers age groups. This zoning technique was applied to avoid over- and under-estimations of the transformers conditions $[14,18,19]$. In total, five zones of transformers age were identified, of which the transition matrix, $\boldsymbol{P}$, was assumed to be homogenous. The last zone of the transition matrix was used for future prediction. For further simplification of the Markov chain process, the final state condition, $P_{55}$, was set as 1 based on the assumption that all transformers would end up in the very poor condition. Next, the future $\mathrm{HI}$ of transformers were computed based on the initial HI condition, as shown in Equation (4).

$$
\boldsymbol{H}_{n+1}=\boldsymbol{H}_{n} \times \boldsymbol{P} \times \boldsymbol{R}^{T}
$$

where $\boldsymbol{H}_{n+1}$ is the next condition at the specific interval, $\boldsymbol{H}_{n}$ is the current condition and $\boldsymbol{R}^{T}$ is the matrix transform of the $\mathrm{HI}$ state condition. The input data for the matrix transform was obtained from Table 1, where $\boldsymbol{R}=$ [100 846946 29]. MM is also able to predict the future condition state for a number of intervals, $t$, from the initial state, $\boldsymbol{H}_{0}$, and transition matrix, $\boldsymbol{P}$, which can be seen in Equation (5). In this study, all transformers at age 0 were considered to be at the initial state where $\boldsymbol{H}_{0}=\left[\begin{array}{lllll}1 & 0 & 0 & 0 & 0\end{array}\right]$ for zone 1 . Since the transformers condition measurements were performed every year, $t$ was set as 1 .

$$
\boldsymbol{H}_{t}=\boldsymbol{H}_{0} \times \boldsymbol{P}^{t}
$$

\subsection{Derivation of Transition Probabilities}

Estimation of the transition probabilities, $P_{i j}$, is crucial since it is the core element of the MM process. The transition probabilities matrix can be determined by heuristic or statistic techniques. In this study, a statistical technique known as the nonlinear optimization technique was implemented. 
The objective of this technique is to identify the values of four parameters, $P_{11}, P_{22}, P_{33}$, and $P_{44}$, that would minimize the absolute differences between the computed and predicted HI data for each transformers group [14,18,37-40]. The function can be seen in Equation (6).

$$
\min \sum_{t=1}^{N}|A(t)-B(t, P)|
$$

where $N$ is the number of year in each zone, $P$ is the transition probabilities $\left(P_{11}, P_{22}, P_{33}, P_{44}\right), A(t)$ is the average or computed $\mathrm{HI}$ at time $t$, and $B(t, P)$ is the predicted values of condition $\mathrm{HI}$ by MM at time $t$. Once the transition matrix in the first zone was determined, the transition probabilities of the second zone were computed based on Equations (5) and (6) through the assumption that the last state condition in the previous zone became the initial state condition for the next. The process was repeated through to the last group of transformer conditions. Finally, the deterioration performance curve was obtained.

\section{Application of Markov Modeling}

In this study, the condition monitoring data from 3195 oil samples measured from 373 transformers with voltage and power ratings of $33 / 11 \mathrm{kV}$ and 30 MVA were tested. The range of the transformers' age was between 1 and 25 years and the distribution of oil samples data can be seen in Figure 3 . The computed $\mathrm{HI}$ of transformers in its age and zone are shown in Table 2.

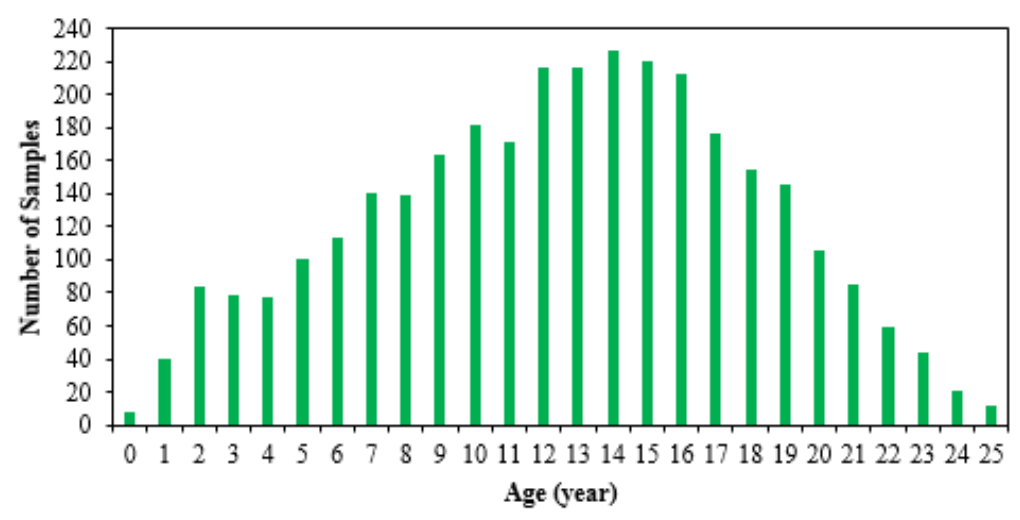

Figure 3. Distribution of oil sample data.

Table 2. Computed HI by age and zones.

\begin{tabular}{cccc}
\hline Zone & Number of Oil Sample & Transformer Age (Year) & Computed HI (\%) \\
\hline \multirow{4}{*}{1} & 40 & 1 & 89.38 \\
& 84 & 2 & 82.80 \\
& 79 & 3 & 82.57 \\
78 & 4 & 69.46 \\
& 101 & 5 & 74.33 \\
\hline \multirow{3}{*}{2} & 113 & 6 & 68.82 \\
& 140 & 7 & 67.60 \\
& 139 & 8 & 65.53 \\
& 164 & 9 & 60.85 \\
& 182 & 10 & 61.09 \\
& 171 & 11 & 56.26 \\
& 216 & 12 & 58.35 \\
& 216 & 13 & 55.59 \\
& 227 & 14 & 54.36 \\
& 220 & 15 & 54.41 \\
\hline
\end{tabular}


Table 2. Cont.

\begin{tabular}{cccc}
\hline Zone & Number of Oil Sample & Transformer Age (Year) & Computed HI (\%) \\
\hline \multirow{4}{*}{4} & 177 & 16 & 53.55 \\
& 154 & 17 & 49.78 \\
& 146 & 18 & 50.24 \\
& 106 & 19 & 48.99 \\
& 85 & 20 & 49.05 \\
\hline 5 & 60 & 21 & 49.18 \\
& 44 & 22 & 50.48 \\
& 21 & 23 & 57.82 \\
& 12 & 24 & 56.80 \\
\hline
\end{tabular}

Next, the nonlinear optimization was performed based on Equation (6). This technique was carried out through the combination of the transition probabilities $\left(P_{11}, P_{22}, P_{33}, P_{44}\right)$, the solution of which was based on the least error count. This technique was adopted in several MM studies for other applications $[14,18,37-40]$. The first two zones of computed HI were used to compute the transition matrix for training and application purposes. The computed HI for zones 3, 4 and 5 were used to validate the predicted HI obtained by the Markov chain algorithm. An example of the first set of the computation for zone 1 is described in the following section. First, the transition matrix in Equation (7) was computed using Equation (6) and Table 2.

$$
\boldsymbol{P}=\left[\begin{array}{ccccc}
0.2889 & 0.7111 & 0 & 0 & 0 \\
0 & 0.7717 & 0.2283 & 0 & 0 \\
0 & 0 & 0.9626 & 0.0374 & 0 \\
0 & 0 & 0 & 0.9900 & 0.0100 \\
0 & 0 & 0 & 0 & 1
\end{array}\right]
$$

Next, the computed transition matrix was used to determine the condition state from years 1 to 5 . The computational process for each year can be seen in Equations (8)-(12).

$$
\begin{aligned}
& \boldsymbol{H}_{1}=\boldsymbol{H}_{0} \times \boldsymbol{P}^{1}=(0.2889,0.7111,0.0000,0.0000,0.0000) \\
& \boldsymbol{H}_{2}=\boldsymbol{H}_{0} \times \boldsymbol{P}^{2}=(0.0835,0.7542,0.1623,0.0000,0.0000) \\
& \boldsymbol{H}_{3}=\boldsymbol{H}_{0} \times \boldsymbol{P}^{3}=(0.0241,0.6414,0.3284,0.0060,0.0000) \\
& \boldsymbol{H}_{4}=\boldsymbol{H}_{0} \times \boldsymbol{P}^{4}=(0.0070,0.5121,0.4626,0.0183,0.0001) \\
& \boldsymbol{H}_{5}=\boldsymbol{H}_{0} \times \boldsymbol{P}^{5}=(0.0020,0.4002,0.5622,0.0354,0.0002)
\end{aligned}
$$

The process was repeated for zone 2 where the last condition state computed in year $t=5$ in Equation (12) was used as an initial condition state for zone 2. Equation (13) shows the transition matrix computed for zone 2.

$$
\boldsymbol{P}=\left[\begin{array}{ccccc}
0.5051 & 0.4949 & 0 & 0 & 0 \\
0 & 0.8923 & 0.1077 & 0 & 0 \\
0 & 0 & 0.7315 & 0.2685 & 0 \\
0 & 0 & 0 & 0.9900 & 0.0100 \\
0 & 0 & 0 & 0 & 1
\end{array}\right]
$$

The transition matrix in Equation (13) was used to predict the future HI for zones 3 to 5 . The initial state in all zones calculated using Equation (5) can be seen in Table 3. 
Table 3. Initial state of each zone.

\begin{tabular}{cccccc}
\hline Zone & \multicolumn{5}{c}{ Initial State } \\
\hline Zone 1 & 1.0000 & 0.0000 & 0.0000 & 0.0000 & 0.0000 \\
Zone 2 & 0.0020 & 0.4002 & 0.5622 & 0.0354 & 0.0002 \\
Zone 3 & 0.0001 & 0.2278 & 0.2136 & 0.5442 & 0.0144 \\
Zone 4 & 0.0000 & 0.1289 & 0.0991 & 0.7261 & 0.0459 \\
Zone 5 & 0.0000 & 0.0729 & 0.0515 & 0.7918 & 0.0838 \\
Zone 6 & 0.0000 & 0.0413 & 0.0282 & 0.8067 & 0.1238 \\
Zone 7 & 0.0000 & 0.0233 & 0.0157 & 0.7969 & 0.1640 \\
\hline
\end{tabular}

The predicted HI obtained by MM for a period of 25 years are shown in Table 4 and Figure 4 . It was found that majority of the predicted HI values are quite close to the computed HI values. There are slight deviations for several of the predicted $\mathrm{HI}$ values at the ages of 3, 4, 24, and 25 years. Further analysis was carried out based on chi-squared goodness-of-fit test, as shown in Equation (14), in order to determine the goodness-of-fit between the computed and predicted HI [18,19].

$$
X^{2}=\sum_{i=0}^{k} \frac{\left(R_{i}-E_{i}\right)^{2}}{E_{i}}
$$

where $k$ is number of observations, $E_{i}$ is the computed value of the $i$ th observation, $R_{i}$ is the predicted value of the $i$ th observation, and $X^{2}$ is a chi-squared distribution coefficient with $k-1$ degrees of freedom. At probability $\alpha$ of $0.05, X^{2}$ is 4.19 , which is lower than the chi-squared critical value, which is 36.42 .

Table 4. Computed and predicted HI.

\begin{tabular}{ccc}
\hline Age & Computed HI (\%) & Predicted HI (\%) \\
\hline 1 & 89.38 & 88.62 \\
2 & 82.80 & 82.90 \\
3 & 82.57 & 79.25 \\
4 & 69.46 & 76.53 \\
5 & 74.33 & 74.35 \\
6 & 68.82 & 70.66 \\
7 & 67.60 & 67.60 \\
8 & 65.53 & 65.02 \\
9 & 60.85 & 62.84 \\
10 & 61.09 & 60.96 \\
11 & 56.26 & 59.34 \\
12 & 58.35 & 57.92 \\
13 & 55.59 & 56.66 \\
14 & 54.36 & 55.56 \\
15 & 54.41 & 54.57 \\
16 & 53.55 & 53.69 \\
17 & 49.78 & 52.89 \\
18 & 50.24 & 52.17 \\
19 & 48.99 & 51.51 \\
20 & 49.05 & 50.91 \\
21 & 49.18 & 50.35 \\
22 & 50.48 & 49.84 \\
23 & 57.82 & 49.37 \\
24 & 56.80 & 48.94 \\
25 & 51.41 & 48.53 \\
\hline
\end{tabular}




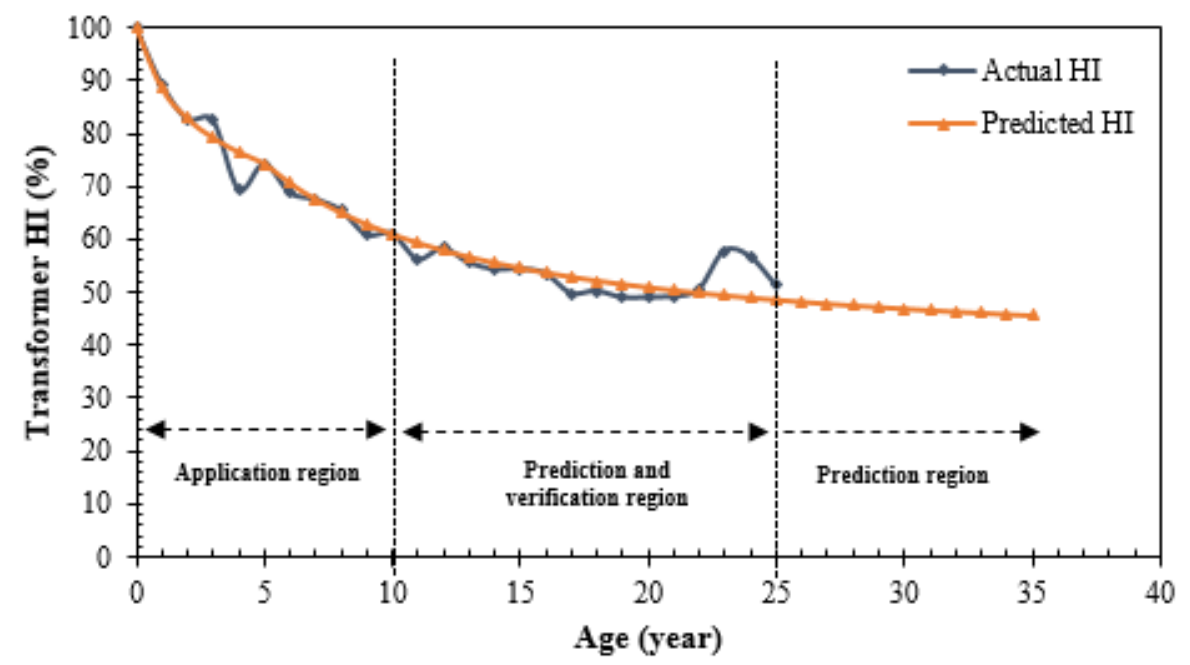

Figure 4. Comparison between computed and predicted HI.

Based on the case study, it was found that the transformer population is in very good and good conditions during the first six years of service, as shown in Table 1 and Figure 4. The transformer population is in fair condition between seven and 21 years of service. After 22 years of service, the transformer population starts to enter poor condition. The prediction reveals that the transformer population remains in poor condition even after 35 years of service. The same analysis as [12] was carried out to determine the average percentage error between the computed and predicted $\mathrm{HI}$ condition curves based on Equation (15), as shown in Figure 5.

$$
\text { Average Percentage Error }(\%)=\frac{\sum_{t=n}^{25}\left(\frac{\left|Y_{n}-X_{n}\right|}{\left|Y_{n}\right|} \times 100\right)}{n}
$$

where $Y_{n}$ is the computed $\mathrm{HI}, X_{n}$ is the predicted $\mathrm{HI}$, and $n$ is the age of the transformer. The overall average percentage error from zones 1 to 5 is $3.59 \%$, while from zones 3 to 5 it is $4.51 \%$. By subtracting $100 \%$ with predicted error determined for zones 3 to 5 , the accuracy of the HI prediction based on $\mathrm{MM}$ for the transformer population is $95.49 \%$. The application of MM to estimate the future states of transformers based on $\mathrm{HI}$ is a promising approach for the assets management of utilities. It is shown that with limited data, MM is able to predict the future states of transformers based on HI. This study can be further validated in the future if the HI from utilities can be obtained. Based on this information, the prediction of $\mathrm{HI}$ can be accurately determined based updated transition probabilities.

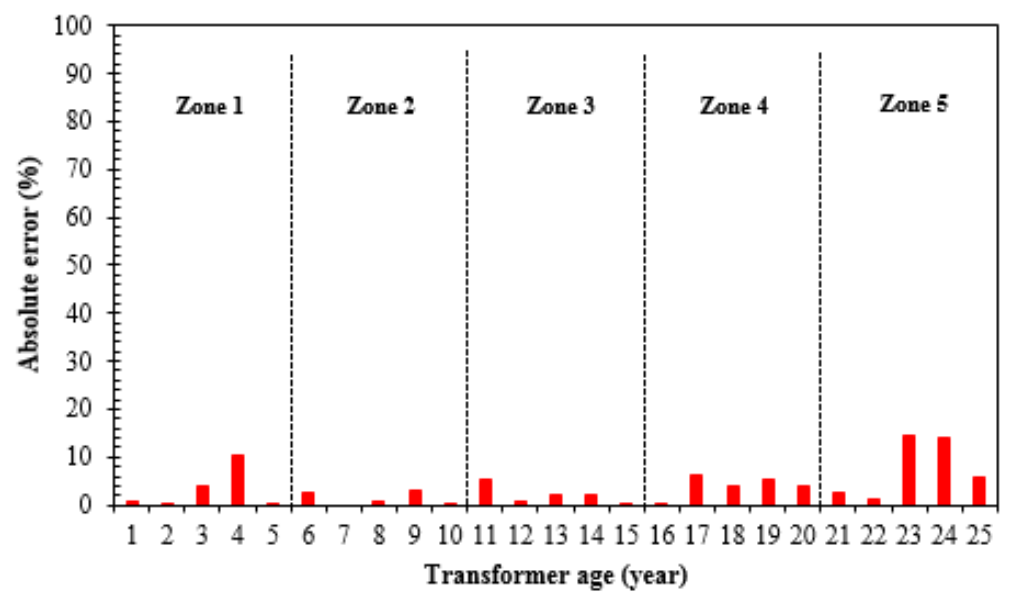

Figure 5. Absolute error between computed and predicted HI. 


\section{Conclusions}

The application of MM to predict the transformers deterioration performance curve based on HI was carried out in this study. It was found that MM can be used to estimate the future states of transformers based on HI. The transition probabilities obtained by the nonlinear optimization technique show that the predicted $\mathrm{HI}$ is quite good and the prediction accuracy could reach up to $95.49 \%$. Based on the predicted HI condition curve, state scale, and recommendations in References [5,6,11,31], the planning for the maintenance, repair, and replacement processes could be considered after 22 years, when the transformer population starts to enter the poor condition. Overall, MM provides a less complex approach for the prediction of transformers $\mathrm{HI}$ and can be easily implemented by utilities that utilize $\mathrm{HI}$ for their optimal asset management strategy. In addition, MM is a dynamic approach where the projected $\mathrm{HI}$ can be updated with the updated transition probabilities.

Acknowledgments: The authors would like to express their sincere gratitude to the Ministry of Higher Education Malaysia, CELP UPM, UTeM, and UPM PUTRA grant scheme for the technical and financial support of this research. Special thanks also to Young Zaidey Yang Ghazali for the technical support.

Author Contributions: The research study was carried out successfully with contributions from all authors. Muhammad Sharil Yahaya was responsible for the main research idea, simulation works and manuscript preparation. Norhafiz Azis contributed on the manuscript preparation and research idea. Mohd Zainal Abidin Ab Kadir, Jasronita Jasni, and Mohd Hendra Hairi provided assistance for finalizing the research work and manuscript. Mohd Aizam Talib gave several suggestions from industrial perspectives. All authors revised and approved the publication of the paper.

Conflicts of Interest: The authors declare no conflict of interest.

\section{References}

1. Emsley, A.; Steven, G. Review of chemical indicators of degradation of cellulosic electrical paper insulation in oil-filled transformers. IEE Proc. Sci. Meas. Technol. 1994, 141, 324-334. [CrossRef]

2. A2.18 W.G. Life Management Techniques for Power Transformer; CIGRE: Paris, France, 2003.

3. Wang, M.; Vandermaar, A.J.; Srivastava, K.D. Review of condition asessment of power transformers in service. Electr. Insul. Mag. IEEE 2002, 18, 12-25. [CrossRef]

4. A2.34 W.G. Guide for Transformer Maintenance; CIGRE: Paris, France, 2011.

5. Jahromi, A.; Piercy, R.; Cress, S.; Service, J.; Fan, W. An approach to power transformer asset management using health index. IEEE Electr. Insul. Mag. 2009, 25, 20-34. [CrossRef]

6. Martins, M.A. Condition and risk assessment of power transformers: A general approach to calculate a health index. Ciência Tecnol. Mater. 2014, 26, 9-16. [CrossRef]

7. Yang Ghazali, Y.Z.; Talib, M.A.; Ahmad Rosli, H. TNB experience in condition assessment and life management of distribution power transformers. In Proceedings of the Electricity Distribution-Part 1 (CIRED 2009), Prague, Czech Republic, 8-11 June 2009; pp. 1-4.

8. Scatiggio, F.; Pompili, M. Health index: The TERNA's practical approach for transformers fleet management. In Proceedings of the Electrical Insulation Conference (EIC), Ottawa, ON, Canada, 2-5 June 2013; pp. 178-182.

9. Taengko, K.; Damrongkulkamjorn, P. Risk assessment for power transformers in PEA substations using Health Index. In Proceedings of the International Conference of Electrical Engineering/Electronics, Computer, Telecommunications and Information Technology (ECTI-CON), Krabi, Thailand, 15-17 May 2013; pp. $1-6$.

10. Tanasescu, G.; Notingher, P.V.; Dragomir, O.; Gorgan, B.; Voinescu, L. Health index calculation of electrical equipments using DiagConsole software. In Proceedings of the Advanced Topics in Electrical Engineering (ATEE), Bucharest, Romania, 23-25 May 2013; pp. 1-6.

11. Haema, J.; Phadungthin, R. Condition assessment of the health index for power transformer. In Proceedings of the IEEE Power Engineering and Automation Conference (PEAM), Wuhan, China, 18-20 September 2012; pp. 1-4.

12. Jiang, Y. Application and comparison of regression and Markov chain methods in bridge condition prediction and system benefit optimization. J. Transp. Res. Forum 2010, 49, 91-110. 
13. Si, X.S.; Wang, W.; Hu, C.H.; Zhou, D.H. Remaining useful life estimation-A review on the statistical data driven approaches. Eur. J. Oper. Res. 2011, 213, 1-14. [CrossRef]

14. Butt, A.A.; Shahin, M.Y.; Feighan, K.J.; Carpenter, S.H. Pavement performance predíction model using the Markov process. Transp. Res. Rec. 1987, 1123, 12-99.

15. Zhou, D.; Wang, Z.; Li, C. Data requisites for transformer statistical lifetime modelling-part I: Aging related failures. IEEE Trans. Power Deliv. 2013, 28, 1750-1757. [CrossRef]

16. Zhou, D.; Wang, Z.; Jarman, P. Data requisites for transformer statistical lifetime modelling-part II: Aging related failures. IEEE Trans. Power Deliv. 2014, 29, 154-160. [CrossRef]

17. Ridwan, M.I.; Talib, M.A.; Ghazali, Y.Z.Y. Application of weibull-bayesian for the reliability analysis of distribution transformers. In Proceedings of the IEEE 8th International Power Engineering and Optimization Conference (PEOCO2014), Langkawi, Malaysia, 24-25 March 2014.

18. Jiang, Y.; Saito, M.; Sinha, K. Bridge performance prediction model using the Markov chain. Transp. Res. Rec. 1988, 1180, 25-32.

19. Jiang, Y.; Sinha, K. Bridge service life prediction model using the Markov chain. Transp. Res. Rec. 1989, 1223, 24-30.

20. Agrawal, A.K.; Kawaguchi, A.; Chen, Z. Deterioration rates of typical bridge elements in New York. J. Bridg. Eng. 2010, 15, 419-429. [CrossRef]

21. Micevski, T.; Kuczera, G.; Coombes, P. Markov model for storm water pipe deterioration. J. Infrastruct. Syst. 2002, 8, 49-56. [CrossRef]

22. Camahan, J.V.; Davis, W.J.; Shahin, M.Y.; Keane, P.L.; Wu, M.I. Optimal maintenance decisions for pavement management. J. Transp. Eng. 1987, 113, 554-572. [CrossRef]

23. Riveros, G.A.; Arredondo, E. Guide to the Development of a Deterioration Rate Curve Using Condition State Inspection Data; Report No.: ERDC/CHL CHETN-IX-25; US Army Corps of Engineers: Davis, CA, USA, 2010; pp. 1-12.

24. Ranjith, S.; Setunge, S.; Gravina, R.; Venkatesan, S. Deterioration prediction of timber bridge elements using the Markov chain. J. Perform. Constr. Facil. 2013, 27, 319-325. [CrossRef]

25. Hamoud, G.A.; Member, S.; Yiu, C. One Markov model for spare analysis of distribution power transformers. IEEE Trans. Power Syst. 2016, 31, 1643-1648. [CrossRef]

26. Li, Q.; Zhao, T.; Zhang, L.; Lou, J. Mechanical fault diagnostics of onload tap changer within power transformers based on hidden Markov model. IEEE Trans. Power Deliv. 2012, 27, 596-601. [CrossRef]

27. Hoskins, R.P.; Strbac, G.; Brint, A.T. Modelling the degradation of condition indices. IEE Proc. Gener. Transm. Distrib. 1999, 146, 386-392. [CrossRef]

28. Hamoud, G.A. Use of Markov models in assessing spare transformer requirements for distribution stations. IEEE Trans. Power Syst. 2012, 27, 1098-1105. [CrossRef]

29. Deloitte Asset Management; Canadian Electricity Associate (CEA). Asset Health Indices: A Utility Industry Necessity; White paper; Deloitte: London, UK, 2014.

30. Brandtzæg, G. Health Indexing of Norwegian Power Transformers. Master's Thesis, Norwegian University of Science and Technology, Trondheim, Norway, 2015.

31. Naderian, A.; Cress, S.; Piercy, R.; Wang, F.; Service, J. An approach to determine the health index of power transformers. In Proceedings of the IEEE International Symposium on Electrical Insulation (ISEI), Vancouver, BC, Canada, 9-12 June 2008; pp. 192-196.

32. Abu-Elanien, A.E.B.; Salama, M.M.A.; Ibrahim, M. Calculation of a health index for oil-immersed transformers rated under $69 \mathrm{kV}$ using fuzzy logic. IEEE Trans. Power Deliv. 2012, 27, 2029-2036. [CrossRef]

33. Ashkezari, A.D.; Ma, H.; Saha, T.K.; Ekanayake, C. Application of fuzzy support vector machine for determining the health index of the insulation system of in-service power transformers. IEEE Trans. Dielectr. Electr. Insul. 2013, 20, 965-973. [CrossRef]

34. Gorgan, B.; Notingher, P.V.; Badicu, L.V.; Tanasescu, G. Calculation of power transformers health indexes. Ann. Univ. Craiova Electr. Eng. Ser. 2010, 34, 13-18.

35. Yates, R.D.; Goodman, D.J. Probability and Stochastic Processes, 2nd ed.; John Wiley \& Sons Inc.: Hoboken, NJ, USA, 2005; pp. 445-451, ISBN 0-471-27214-0.

36. Shannon, C.E. A mathematical theory of Communication. Bell Syst. Tech. J. 1948, 27, 379-423. [CrossRef]

37. Davis, W.J.; Carnahan, J.V. Decision support for road surface maintenance. Omega 1987, 15, 313-322. [CrossRef] 
38. Morcous, G. Performance prediction of bridge deck systems using Markov chains. J. Perform. Constr. Facil. 2006, 20, 146-155. [CrossRef]

39. Cesare, M.A.; Santamarina, C.; Turkstra, C.; Vanmarcke, E.H. Modeling bridge deterioration with Markov chains. J. Transp. Eng. 1993, 118, 820-833. [CrossRef]

40. Zhang, Y.; Augenbroe, G.; Vidakovic, B. Uncertainty analysis in using Markov Chain to predict roof life cycle performance. In Proceedings of the Durability of Building Material and Components (10DBMC), Lyon, France, 17-20 April 2005.

(c) (1)

(C) 2017 by the authors. Licensee MDPI, Basel, Switzerland. This article is an open access article distributed under the terms and conditions of the Creative Commons Attribution (CC BY) license (http:/ / creativecommons.org/licenses/by/4.0/). 